\title{
PIBID SUBPROJETO LETRAS ESPANHOL: PERCEPÇÕES E CONTRIBUIÇÕES ADVINDAS DOS ESTUDOS DE PAULO FREIRE
}

\author{
Gisélia Pereira Morin* \\ Ivani Cristina Silva Fernandes **
}

\begin{abstract}
RESUMO:
O presente trabalho objetiva refletir sobre a proposta freireana de educação imbricadas nas intervenções realizadas pelo PIBID Subprojeto Letras Espanhol, durante o segundo semestre de 2016 e apresentar as contribuições que tal perspectiva trouxe para o subprojeto e para o ensino e aprendizagem de E/LE. Como aportes teóricos foram utilizados os estudos de Freire (2016), Botton e Armstrong (2014), Marcuschi (2008) e Flores (2012). Para atender os objetivos, optou-se pela pesquisa qualitativa. Em síntese, acredita-se que o trabalho contribuirá no processo de formação dos pibidianos, uma vez que proporciona reflexão sobre a prática, contribuindo para o processo de ensino de língua estrangeira, pois ao aproximar e problematizar a sala de aula e a realidade escolar, o aprendizado torna-se significativo.
\end{abstract}

PALAVRAS-CHAVE: Educação. PIBID. Ensino e aprendizagem. E/LE. Aprendizado significativo.

\begin{abstract}
:
The paper have the objectives of to reflect about the Freirean Proposal of Education in the interventions made by PIBID Subprojeto Letras / Espanhol, in the second time of 2016 and to introduce contributions that the perspective brought for the subproject and teaching and learning of E/LE. How the theoretical contributions be used of Freire's studies (2016), Botton's and Armstrong's (2014), Marcuschi's (2008) and Flores's (2012). For to reach the objectives made the use of Qualitative Research. Is believed that the paper does support of pibidianos and for the teaching process of foreign language, because when problematizing and approaching the classroom for the school reality, the learning becomes significant.
\end{abstract}

KEYWORDS: Education. PIBID. Teaching and Learning. E/LE. Significant Learning.

\section{Introdução}

O presente trabalho tem como objetivo refletir sobre a proposta freireana de Educação Libertadora que estavam imbricadas nas intervenções do PIBID Subprojeto Letras / Espanhol, realizadas durante o segundo semestre de 2016 com alunos do $8^{\circ}$ e $9^{\circ}$ ano de uma escola localizada na zona leste da cidade de Santa Maria. Tal intervenção consistiu, em um primeiro momento, da aplicação de um questionário diagnóstico. Em seguida, realizaram-se as apresentações dos conceitos de "Instante Decisivo" e de "Microconto".

Ademais, busca-se apresentar as contribuições no que se refere ao pensar a prática educativa na presente perspectiva para o ensino e aprendizagem de E/LE e como tal perspectiva contribuiu para o processo de formação dos pibidianos.

Para melhor contextualizar, as intervenções do projeto PIBID foram realizadas em 2016 e as leituras sobre Educação Libertadora, de Freire (2016) se realizaram no inicio do presente ano como atividades do grupo. Nesse sentido, após reflexões, percebeu-se que as intervenções contemplavam as propostas apresentadas por Freire.

\footnotetext{
* Autora. Graduada em Letras Espanhol e Literaturas de Língua Espanhola, pela Universidade Federal de Santa Maria e pós-graduanda do Curso de Especialização em Tecnologias da Informação e da Comunicação Aplicadas à Educação, pela UFSM. Integrante do PIBID Subprojeto Letras / Espanhol. E-mail: mgiselia609@gmail.com ** Coautora e Orientadora. Prof ${ }^{a}$ Dr $^{a}$ do Departamento de Letras Estrangeiras e Modernas, da Universidade Federal de Santa Maria. Coordenadora do PIBID Subprojeto Letras / Espanhol. E-mail: icrisifer@gmail.com
} 
Cabe explanar que a presente pesquisa originou-se após os estudos de Paulo Freire, realizadas pelo PIBID Subprojeto Letras / Espanhol - UFSM, no inicio do presente ano. Para melhor situar os leitores, o Programa Institucional de Bolsa de Iniciação à Docência (apoiado pela CAPES) tem como um de seus objetivos o aprimoramento da qualidade do processo de ensino-aprendizagem na escola pública por meio da inserção dos licenciandos na realidade escolar. Diante disso, entende-se que o papel da universidade é buscar uma interação com as escolas de educação básica com o propósito de, por um lado, aprimorar a relação teoria/prática no espaço acadêmico, e, por outro, oferecer oportunidades de atualização constante aos professores que atuam nas redes públicas de ensino. Em consonância com tais aspectos, o PIBID Subprojeto Letras / Espanhol, a partir das noções de alteridade, diversidade e heterogeneidade, busca contribuir para a formação docente na área de Espanhol como Língua Estrangeira (E/LE) por meio da reflexão teórica, do estudo de problemas concretos, da intervenção pedagógica e da ressignificação de experiências.

No sentido de dar continuidade, as leituras realizadas foram discutidas em reuniões semanais e tais discussões geraram problematizações e inquietações sobre as futuras práticas e sobre as intervenções já realizadas.

Neste contexto, muitos foram os questionamentos de modo que se percebeu a necessidade de refletir e problematizar as ações realizadas em aula pelo grupo e em que medida elas estavam de acordo com a proposta freireana.

De acordo com isso, o presente estudo expõe, na primeira parte, os aportes teóricos que deram corpo ao estudo, as discussões, as pesquisas e aos questionamentos. $\mathrm{Na}$ continuação, a segunda parte do trabalho abordará a metodologia utilizada para concretizar as pesquisas.

$\mathrm{Na}$ terceira parte deste estudo, encontram-se algumas informações pertinentes as intervenções do subprojeto, como foram realizadas etapa por etapa, com a finalidade de proporcionar um melhor entendimento das atividades.

Já na quarta e última parte, pontuam-se a análise e as discussão dos dados, bem como a pertinência do estudo para o grupo e para o processo de ensino e aprendizagem.

\section{Pressupostos teóricos}

No decorrer da pesquisa recorreu-se aos estudos de Ludke; André (1986) e Neves (1996) para falar da abordagem qualitativa; Marcuschi (2008) para embasar os estudos sobre gênero textual; Botton \& Armstrong (2014) e Tassinari (2008) para delinear os estudos sobre fotografia; Flores (2012), para dar conta das discussões sobre Linguística da Enunciação; e Freire (2016) para refletir sobre Educação Libertadora, que esteve presente nas intervenções do subprojeto. Cabe destacar que a presente pesquisa baseia-se nos Parâmetros Curriculares Nacionais (2000), as Orientações Curriculares para o Ensino Médio (2006) e no Referencial Curricular Lições do Rio grande (2009).

\section{Metodologia}

A abordagem metodológica que norteia o presente estudo classifica-se como qualitativa. As autoras Ludke e André (1986), baseadas nas pesquisas de Bogdan e Biklen (1982), afirmam que "a pesquisa qualitativa supõe o contato direto e prolongado do pesquisador com o ambiente e a situação que está sendo investigada" (LUDKE \& ANDRÉ, 1986, p. 11). Nesse sentido, a pesquisa qualitativa ela:

não busca enumerar ou medir eventos e, geralmente não emprega instrumental estatístico para análise dos dados, seu foco de interesse é 
amplo e parte de uma perspectiva diferenciada da adotada pelos métodos quantitativos, dela faz parte a obtenção de dados descritivos mediante contato direto e interativo do pesquisador com a situação do objeto estudado (NEVES, p. 1, 1996).

De acordo com isso, o subprojeto iniciou as intervenções com a aplicação de um questionário, com o intuito de coletar informações prévias sobre os conhecimentos dos educando. Com base nos dados obtidos, o grupo delineou a proposta de articulação entre microconto e instante decisivo.

Tal proposta foi realizada no segundo semestre de 2016, na Escola Estadual de Educação Básica Professora Margarida Lopes, com os alunos de $8^{\circ}$ e $9^{\circ}$ ano do ensino fundamental. $\mathrm{O}$ objetivo das intervenções consistiu em trabalhar a materialidade da língua espanhola em sala de aula a partir de um olhar interdisciplinar. Desse modo, a primeira atividade desenvolvida foi à aplicação de um questionário diagnóstico, na qual se buscou conhecer o perfil dos educandos.

Assim, a proposta do subprojeto consistiu na articulação de dois conceitos presentes nas áreas da Fotografia e da Literatura: instante decisivo, representado pelo fotógrafo francês Henri Cartier-Bresson (1908-2004) e microconto, cujo principal representante é o guatemalteco Augusto Monterroso (1921-2003).

Nesse contexto, os bolsistas de iniciação à docência iniciaram as intervenções com a apresentação do conceito fotográfico Instante decisivo, passando para a apresentação do gênero textual microconto. As intervenções ocorreram semanalmente, contando com 2horas/aula. Como materiais didáticos, os pibibianos elaboraram arquivos em PowerPoint, materiais com atividades escritas para fixação, além de promover diálogos e disponibilizar tempo para orientações individuais em aula no que se referia a escrita dos microcontos.

Após a finalização das produções, o grupo organizou uma exposição para apresentar a comunidade escolar o produto final das intervenções. Concomitante com o período de organização da exposição, o grupo PIBID Subprojeto Letras / Espanhol começou os estudos de Paulo Freire. Com esse espaço para a leitura e para discussões, foi possível refletir, problematizar e avaliar as atividades realizadas pelo grupo até o presente momento.

\section{A intervenção: conceituando Instante Decisivo e Microconto}

A intervenção do PIBID no respectivo ano foi à articulação entre o conceito literário de Microconto e o conceito fotográfico de Instante Decisivo, gerando como produto final uma exposição fotográfica dos trabalhos dos alunos.

Nesse sentido, destaca-se que, de acordo com Silva, Campos e Silva (2017):

os microcontos possibilitam a oportunidade dos alunos se deleitarem em uma leitura que requer pouco tempo, mas não deixa de causar seus efeitos positivos. Já que é notório o pouco interesse pela leitura, os alunos podem se interessar por uma leitura que não passa de uma linha. A concisão é uma das vantagens deste gênero, pois a atividade de leitura pode ser praticada, a fim de se trabalhar o seu aperfeiçoamento e, por conseguinte a construção de sentidos. (SILVA, CAMPOS e SILVA, 2017, p. 611).

Ou seja, foi pensando em tais aspectos que se optou pelo gênero textual microconto, uma vez que este é conciso, de fácil leitura e que exige dos leitores atenção e concentração para a obtenção de sentido. Segundo Seabra (2017), o precursor dos microcontos foi o guatelmateco Augusto Monterroso. Ainda segundo o autor, o microconto mais famoso foi $\mathrm{El}$ 
dinosaurio. Monterroso consolidou tal vertente desafiando a escrita de maneira sucinta e impactante (SEABRA, 2017, s/p).

Segundo Álveres (2012), os microcontos, também conhecidos como microrrelatos ou minicontos, ou ainda "textos literários breves e hiperbreves" (ÁLVERES, 2012, s/p), são definidos "por três constantes: a brevidade, a narratividade - estas duas explicitamente presentes na designação micronarrativa - e a intertextualidade" (ÁLVERES, 2012, s/p), de modo que não fazem descrições espaciais, não apresentam fluxo de memória, apresentando um contexto inicial, um clímax e um desenlace.

$\mathrm{Na}$ escrita e na produção textual de microcontos, "o importante é estabelecer apenas um núcleo significativo" (CAMPOS, 2011). Em outras palavras, não há necessidade de nomear os personagens, de definir suas características, bastando apenas à referência de um personagem. Também, não há necessidade de explicações, delimitação de espaço ou tempo da ação. "é o leitor quem preencherá as fendas deixadas, propositadamente, pelo narrador" (CAMPOS, 2011) a partir da subjetividade na escrita.

Indo ao encontro das características do microconto, o autor coloca que "de todos os meios de expressão, a fotografia ê o único que fixa um momento preciso" (CARTIERBRESSON, 2004, p. 18), sendo essa a definição para o conceito de instante decisivo, que se encaixa ao de microconto na medida em que possui como principal característica a instantaneidade. Ou seja, capturar uma imagem/foto em que o movimento esteja registrado e eternizado, sendo que "o escritor tem o tempo de refletir antes que a palavra se forme, antes de deitá-la sobre o papel... Para nós, o que desaparece, desaparece para sempre" (CARTIERBRESSON, 2004, p. 19), por isso a integração da fotografia com o microconto.

Assim, o microconto por ser "uma narrativa curta, leva o leitor a imaginar a situação trazendo múltiplas interpretações. Um dos recursos estilísticos mais usados pelos seus autores são as figuras de linguagem, principalmente, a ambiguidade, a ironia e a metáfora" (RODRIGUES; SOUZA, 2013, p. 90). Já o instante decisivo, capta a instantaneidade da vida cotidiana, eternizando-a em uma imagem.

Tal articulação, culminada na exposição Olhares Essenciais possibilitou que os alunos se interessassem mais pela leitura e consequentemente, por buscar a subjetividade do autor nos microcontos e nas fotografias. Ademais, foi possível com a articulação de ambos os conceitos que os alunos adquirissem conhecimentos de maneira contextualizada, de modo que puderam exercer sua autonomia no processo de aprendizagem, sendo ativos na captura da fotografia e na sua subjetividade na escrita dos microcontos, podendo ainda se manifestar de maneira crítica, irônica e/ou reflexiva.

\section{Intervenções do PIBID Subprojeto Letras / Espanhol}

Nesta seção, buscam-se apresentar detalhadamente como foram realizadas as intervenções do PIBID subprojeto Letras / Espanhol, realizadas no segundo semestre de 2016 em uma escola estadual localizada na zona leste de Santa Maria e refletir sobre como as concepções apresentadas por Paulo Freire (2016) estiveram imbricadas nas ações do subprojeto.

Para iniciar, no segundo semestre de 2016 o grupo contou com seis bolsistas de iniciação à docência, um bolsista colaborador e uma bolsista supervisora (regente das turmas de oitavo e nono ano do ensino fundamental). Primeiramente, como explanado anteriormente, os pibidianos observaram algumas aulas e aplicaram um questionário para coletar informações sobre os educandos e, consequentemente, conhecer um pouco dos alunos.

Em um segundo momento, realizaram-se intervenções na escola para apresentar o conceito fotográfico de instante decisivo. Para isso, foram utilizados como materiais de apoio um PowerPoint (elaborado pelos bolsistas), fotografias e imagens representativas do conceito 
e um material impresso com atividades para fixação. Destaca-se aqui que, segundo Botton e Armostrong (2014), ao trabalhar com o conceito fotográfico em sala de aula os alunos adquirem novos conhecimentos sobre assuntos que estão no dia a dia, uma vez que a prática de fotografar é recorrente nos dias atuais. Ademais, o novo conceito apresentado incrementa a percepção sobre fotografia (para além do selfie). Nesse sentido, os alunos puderam ter contato com obras de artes, de modo que se sentem motivados a criar suas próprias fotografias.

A partir das intervenções, chamou-se a atenção dos educandos para ir além da fotografia, ou seja, compreender a foto como uma obra artística que representa uma realidade específica, contendo significados e representações, de modo que "uma boa obra artística capta o núcleo da significação" (BOTTON; ARMOSTRONG, 2014, p. 10), alertando os educandos a captarem a essência e os detalhes dos momentos registrados.

Em um terceiro momento, o grupo fez inserções nas turmas para apresentar o conceito de microconto. Cabe destacar que, pensou-se em trabalhar com o gênero textual microconto, por este ser um gênero textual curto e que melhor se relaciona com as características de instante decisivo, como já mencionado anteriormente.

Salienta-se que, para este trabalho, considerou-se como gênero a definição advinda dos estudos de Marcuschi (2008, p. 155), em que

\begin{abstract}
Os gêneros textuais são os textos que encontramos em nossa vida diária e que apresentam padrões sociocomunicativos característicos definidos por composições funcionais, objetivos enunciativos e estilos concretamente realizados na integração de forças históricas, sociais, institucionais e técnicas [...], são formas textuais escritas ou orais bastante estáveis, históricas e socialmente situadas. (MARCUSCHI, p. 155, 2008).
\end{abstract}

Entende-se que os gêneros não podem ser considerados como formas estanques e rígidas, mas sim, “devem ser visto na relação com as práticas sociais, os aspectos cognitivos, os interesses, as relações de poder, as tecnologias, as atividades discursivas e no interior da cultura" (MARCUSCHI, 2011, p. 19), de modo que podem mudar, variar e fundir com outros, mantendo sua funcionalidade em determinado contexto.

Em um quarto momento, realizou-se a parte prática da proposta. Em grupos, os educandos tiraram suas fotos características de um momento decisivo e, a partir de reflexões sobre tal fotografia, elaboram seus microcontos.

Assim sendo, o PIBID Subprojeto Letras / Espanhol, ao possibilitar aos educandos o contato e a produção de textos em língua estrangeira, segue os postulados da Linguística da Enunciação, sendo que se propõe a:

\footnotetext{
tomar como objeto de estudo o enunciado, não visto isoladamente, como unidade de sentido, mas como subunidade do texto, com relações internas entre seus segmentos e relações externas com outros enunciados no texto. Tais trabalhos interessam-se tanto pela identidade do enunciado no conjunto do texto quanto pela construção do sentido que a sucessão de enunciados, nas relações que mantêm entre si, produz nesse âmbito mais amplo. (FLORES e TEIXEIRA, 2012, p. 93).
}

De tal modo, os textos produzidos pelos educandos possuem as marcas da subjetividade, sendo que cada aluno se marcou na produção escrita e nas fotografias. Nesse sentido, considera-se para o processo de elaboração textual "o sujeito, tempo e espaço" (FLORES, 2001 apud FLORES; TEIXEIRA, 2012, p. 107), de modo que os pibidianos auxiliam os alunos nas produções, sem interferir nos efeitos de sentidos que cada grupo buscava inferir nas produções.

Como produto final das intervenções, realizou-se a montagem e exposição Olhares essenciais, que se realizou na escola de maneira a divulgar as produções dos alunos para a comunidade escolar. 


\section{Análise e discussões dos dados}

Esta seção dará conta de fazer uma reflexão com comentários analíticos de como as atividades do supracitado projeto se encaixaram na perspectiva freireana sobre Educação Libertadora e como tal perspectiva contribuiu para o subprojeto e para o ensino e aprendizagem de E/LE.

Para iniciar, destaca-se, em primeiro lugar, que se considera o conhecimento "como uma aventura para a qual a educação deve fornecer o apoio indispensável" (MORIN, 2001, p. 31). Dessa maneira, o PIBID Subprojeto Letras / Espanhol oportunizou, por intermédio dos dois conceitos apresentados aos educandos, a ampliação de experiências, uma vez que, ao buscar momentos específicos para fotografar, foi possível que cada aluno pudesse se expressar de maneiras diferentes.

Um dos saberes indispensáveis para a prática educativa referenciada por Freire elucida que "ensinar não é transferir conhecimento, mas criar as possibilidades para a sua produção ou a sua construção" (FREIRE, p. 24, 2016). De acordo com a ideia apresentada, o subprojeto, na organização da proposta de intervenção, buscou elaborar suas atividades de maneira que instigasse a curiosidade dos educandos, possibilitando que eles buscassem o conhecimento.

As atividades propostas nas intervenções mobilizaram os conhecimentos que os estudantes já possuíam e, a partir deles, foram acrescentados novos. Com relação a isso, Freire (2016) destaca a importância de "respeitar a leitura de mundo do educando para ir mais além dela" (FREIRE, 2016, p. 120), ou seja, valorizar os saberes que os alunos já possuem, suas experiências e suas dúvidas, para assim, direcionar os alunos para novos saberes e experiências, de modo que ampliem seus conhecimentos. Segundo Freire (2016), "ensinar exige respeito aos saberes dos educandos".

Nesse contexto, a utilização de um conceito advindo da área da arte tornou-se coerente com o proposto, uma vez que se leva em consideração que "a arte é uma forma de preservar experiências" (BOTTON; ARMOSTRONG, 2014, p. 10). Assim, as fotografias representativas do conceito de instante decisivo foi uma alternativa encontrada pelo grupo para que os alunos pudessem, enquanto cidadãos, estar representados em sala de aula e adquirir conhecimentos específicos.

De acordo com Paulo Freire (2016, p. 96), "ensinar exige compreender que a educação é uma forma de intervenção no mundo", uma vez que ao levar para sala de aula uma foto do dia-a-dia, valorizam-se os saberes, as culturas e as vivencias dos alunos, tornando o processo de ensino e de aprendizagem significativo. Destaca-se também que relacionar os conhecimentos de uma língua estrangeira com o cotidiano aproxima a sala de aula do espaço social e cria novas experiências de estar e perceber o mundo ao redor. Possibilita também, "um posto de observação fenomenal, muito importante e abrangente, de onde se examinam as vicissitudes da condição humana" (BOTTON; ARMOSTRONG, 2014, p. 30).

Cabe destacar que, muitas vezes, é por meio das fotografias que se conhece quem realmente é e os sentimentos que ficam camuflados no interior de cada um (BOTTON; ARMOSTRONG, 2014). Em sala de aula, ao analisar as fotografias, os educados refletem sobre a foto, buscam detalhes que passaram despercebidos, fazem questionamentos, buscam diversas maneiras de olhar a mesma imagem e deixam sua subjetividade na escrita dos microcontos, sendo que se consideram nas produções as marcas do sujeito no enunciado e a combinação de forma e sentido (FLORES, 2012), ou seja, articular "uma linguagem que não apenas se vale do instantâneo, mas que também o significa" (TASSINARI, 2008, p.10). Tal pressuposto também é orientado pelas Orientações Curriculares Nacionais, quando estas expõem que "é fundamental trabalhar as linguagens não apenas como formas de expressão e 
comunicação, mas como constituintes de significados, conhecimentos e valores" (BRASIL, 2006, p. 131).

Assim, as intervenções possibilitaram o exercício da reflexão e da escrita em língua estrangeira, de modo que ao final do trabalha percebeu-se que cada estudante teve a oportunidade de crescer e se reconhecer como agente em sala de aula, uma vez que:

não somos transparentes com nós mesmos. Temos intuições, suspeitas palpites, vagas reflexões e emoções estranhamente contraditórias, e tudo isso resiste a uma definição simples. Temos estados de espírito que não conhecemos bem. Aí, de vez em quando, topamos com obras de arte que parecem agarrar algo que sentíamos, mas que nunca havíamos notado com clareza (BOTTON; ARMOSTRONG, 2014, p. 44).

Pode-se dizer, segundo os autores, que a arte é "um guia para o autoconhecimento [...] um guia para a ampliação da experiência [...] um instrumento de recuperação da sensibilidade" (20114, p. 65), pois oportuniza o papel de ser protagonista da própria história e do próprio aprendizado.

No que se refere ao processo de escrita dos microcontos, o processo se deu de maneira satisfatória, uma vez que os alunos tiveram que produzir a partir de um dado concreto, suas próprias fotos. Nesse sentido, considera-se que, segundo as OCEMs

a disciplina Línguas Estrangeiras na escola visa a ensinar um idioma estrangeiro e, ao mesmo tempo, cumprir outros compromissos com os educandos, como, por exemplo, contribuir para a formação de indivíduos como parte de suas preocupações educacionais. (BRASIL, 2006, p. 91).

Nesse sentido, as atividades desenvolvidas com os educandos do Ensino Fundamental pelo subprojeto se justificam pela tentativa de integração da língua estrangeira a uma forma de criar e recriar a realidade dos educandos e de pensar e repensar os modos como os sujeitos interagem com o mundo e com o outro. Revuz (1997) destaca que o eu da língua estrangeira não é o eu da língua materna. De acordo com o Referencial Curricular Lições do Rio Grande, o ensino de línguas na escola proporciona aos educandos

compreender melhor a sua própria realidade e aprender a transitar com desenvoltura, flexibilidade e autonomia no mundo em que vivem e, assim, serem indivíduos cada vez mais atuantes na sociedade contemporânea, caracterizada pela diversidade e complexidade cultural. (RIO GRANDE DO SUL, 2009, p. 127).

Destaca-se também a iniciativa de estimular os alunos a considerarem a língua estrangeira como um importante aspecto na construção de si e do outro, sendo que "a sala de aula de línguas adicionais é um bom lugar para descobrir quem se é, porque se está necessariamente encontrando um outro nessa língua outra" (RIO GRANDE DO SUL, 2009, p. 134).

Ademais, a perspectiva de Educação Libertadora apresentada por Freire (2016) contribuiu para o subprojeto de modo que os pibidianos puderam pensar nas suas ações e "ampliar suas percepções trazendo propostas de novos conhecimentos, materiais e formas de ver as coisas, a fim de aguçarem seus processos perceptivos" (NUNES, 2011, p. 138).

No que se refere às contribuições para o ensino e aprendizagem de E/LE, foi a partir das atividades desenvolvidas pelo subprojeto que os educandos tornam-se ativos e preparamse para assumirem o lugar de cidadãos, compreendendo e vivenciando a alteridade, a diversidade e a heterogeneidade dentro da comunidade, como orientado pelas Orientações Curriculares Nacionais para o Ensino Médio, em que, para o ensino de língua estrangeira fazse necessário "um sentido que supere o seu caráter puramente veicular, dar-lhe um peso no 
processo educativo global desses estudantes, expondo-os à alteridade, à diversidade, à heterogeneidade, caminho fértil para a construção da sua identidade" (BRASIL, 2006, p. 129).

Por último, pensando no processo de articulação entre instante decisivo e microconto, os integrantes do subprojeto decidiram realizar a atividade juntamente com os alunos, para assim, também experienciar a proposta. De acordo com tal atitude, Freire (2016) destaca que "as palavras a que falta corporeidade do exemplo pouco ou quase nada valem", de modo que os alunos percebam a sala de aula como um ambiente propício para o aprendizado, sendo este um processo lento e satisfatório.

\section{Considerações finais}

Realizou-se neste estudo uma apresentação das intervenções do PIBID Subprojeto Letras / Espanhol desenvolvidas em uma escola estadual da cidade de Santa Maria, Rio Grande do Sul e, a partir disso, foi realizada uma reflexão para identificar os momentos em que as intervenções estiveram de acordo com a perspectiva freireana de educação libertadora.

De acordo com isso, conclui-se que, mesmo sem ter a base teórica que orientava o trabalho para tal perspectiva, o subprojeto elaborou e desenvolveu na escola uma proposta de trabalho centrada na formação de educandos autônomos e conscientes.

Percebe-se que as intervenções eram orientadas pelo diálogo com os educandos, de modo que, segundo Freire (1983) proporcionar espaço para o diálogo em sala é essencial, uma vez possibilita que os alunos se expressem a partir das vivencias e que problematizem a realidade em que estão inseridos, para que possam compreender e transformar os conhecimentos experienciais em conhecimentos científicos.

Com o conceito fotográfico, possibilitou-se a ampliação dos saberes que os alunos tinham sobre fotografia, como também, colocou-os em um novo patamar de conhecimento, dando um significado para a produção escrita.

Ao pensar a proposta de trabalhar com um gênero textual em sala de aula, promove-se o desenvolvimento cognitivo e pessoal dos alunos, pois exige leitura, reflexão e concentração, de modo que "o ensino com base em gêneros deveria orientar-se mais para aspectos da realidade do aluno" (MARCUSCHI, 2011, p. 31), tornando o processo de aprendizagem pautado em um contexto real e significativo com a utilização das fotos.

Cabe destacar também que todas as atividades desenvolvidas com os educandos foram esclarecidas desde o inicio das intervenções, inclusive, todos estavam conscientes que suas produções comporiam a exposição Olhares Essenciais na escola. Em referência a isso, Edgar Morin destaca que "é preciso situar as informações e os dados em seu contexto para que adquiram sentido" (MORIN, 2001, p. 36), tornando o processo de criação e escrita motivador aos alunos.

Nesse sentido, "todo conhecimento deve contextualizar seu objetivo para ser pertinente" (MORIN, 2001, p. 47), pois quando o aluno sabe qual o motivo de produzir em sala de aula, qual será o produto final e onde será exibido, todo o conhecimento adquirido torna-se relevante e instiga a curiosidade e o interesse dos mesmos.

Para finalizar, conclui-se que promover uma Educação Libertaria é possível e gratificante tanto para professores como para alunos, sendo que ambos passam por um processo de aprendizagem, pois segundo Freire (2016, p. 25) "quem ensina aprende ao ensinar e quem aprende ensina ao aprender".

Com a presente reflexão, o grupo PIBID Subprojeto Letras / Espanhol pode refletir, discutir e problematizar suas futuras ações na escola, para tornar a teoria coerente com a prática. Destaca-se também que as leituras contribuíram para tornar os integrantes do grupo 
mais críticos com relação às suas práticas em sala de aula e preocupando-se com a formação de alunos conscientes e autônomos.

Desta maneira, compreende-se que a aprendizagem deve ser "como um processo complexo e interativo, que se constitui na relação do sujeito com as situações concretas nas quais está inserido" (NUNES, 2011, p. 17). Em outras palavras, a aprendizagem não deve ser isolada do contexto em que o estudante está inserido, de modo que o trabalho com gêneros textuais propicia um aprendizado significativo para os educandos, abrindo possibilidades para trabalhar de forma contextualizada, aproximando a língua do meio em que os estudantes estão inseridos.

\section{Referências}

ÁLVERES, Cristina. Quatro dimensões do microconto como mutação do conto: brevidade, narratividade, intertextualidade, transficcionalidade. GUAVIRA LETRAS, n. 15, ago. / dez. 2012.

BOTTON, A.; ARMOSTRONG, J. Arte como terapia. Rio de Janeiro: Intrínseca, 2014. 240 p.

BRASIL. Orientações curriculares para o Ensino Médio: Conhecimentos de Língua estrangeira e Conhecimentos de espanhol. Brasília: MEC/SEF, 2006.

. Parâmetros Curriculares Nacionais: Língua Estrangeira. MEC, 2000.

CARTIER-BRESSON, Henri. O imaginário segundo a natureza. Trad. Renato Aguiar.

Editorial Gustavo Gilio AS: Barcelona, 2004.

CAMPOS, Luciene L. de. Entre frinchas, a poética do microconto brasileiro. XII Congresso Internacional da ABRALIC Centro, Centros - Ética, Estética. UFPR: Curitiba, 2011.

FLORES, V. N.; TEIXEIRA, M. Introdução à Linguística da Enunciação. $2^{\mathrm{a}}$ ed. São Paulo: Contexto, 2012. 125 p.

FREIRE, Paulo. Pedagogia da autonomia: saberes necessários à prática educativa. $53^{\mathrm{a}}$ ed. Rio de Janeiro: Paz e Terra, 2016. 143 p.

. Pedagogia do oprimido. 62 a ed. Rio de Janeiro: Paz e Terra, 2016.

. Extensão ou comunicação? $7^{\mathrm{a}}$ ed. Tradução de Rosisca Darcy de Oliveira. Rio de Janeiro, Paz e Terra, 1983. 93 p.

LIMA, PRISCYLLA A; LAGO, NEUDA A. do. A importância da pedagogia crítica no ensino de língua estrangeira moderna. Textos Completos: II Congresso Internacional de História da UFG/Jataí: História e Mídia. Jataí, 2008.

LÜDKE, M. e ANDRÉ, M. E. D. A. Pesquisas em Educação: abordagens qualitativas. São Paulo: EPU, 1996.

MARCUSCHI, L. A. Produção Textual, Análise de Gêneros e Compreensão. São Paulo: Parábola Editorial, 2008. 
Gêneros textuais: configuração, dinamicidade e circulação. In: KARWOSKI, A. M; GAYDECZKA, B; BRITO, K. S (Org). 4ª ed. São Paulo: Parábola Editorial, 2011.

MORIN, E. Os sete saberes necessários à educação do futuro. $3^{\mathrm{a}}$ ed. São Paulo: Cortez; Brasília: UNESCO, 2011. 118 p.

NEVES, J. L. Pesquisa qualitativa: características, usos e possibilidades. In: Caderno de Pesquisa em Administração. São Paulo, vol.1, n³, 1996. Disponível em:<http://ucbweb.castelobranco.br/webcaf/arquivos/15482/2195/artigo_sobre_pesquisa_qual itativa.pdf $>$. Acesso em: 19 mar. 2017.

NUNES, Ana Ignez Belém Lima. Aprendizagem: um conceito histórico e complexo. IN: Psicologia da aprendizagem: processos, teorias e contextos. Brasília: Liber Livros, 2011, p. 11-19.

Os processos psicológicos e a aprendizagem humana. IN: Psicologia da aprendizagem: processos, teorias e contextos. Brasília: Liber Livros, 2011, p. 133-145.

PASSARELLI, L.M.G. Ensino e correção na produção de textos escolares. São Paulo: Cortez, 2012.

REVUZ, C. A língua estrangeira entre o desejo de um outro lugar e o risco do exílio. In: SIGNORINI, I. (Org.). Linguagem e Identidade: Elementos para uma discussão no campo aplicado. São Paulo: Mercado das Letras, 1998. p.213-230.

RODRIGUES, Gisele dos S; SOUZA, Cristiane S. de. Microcontos digitais: experiências em uma escola pública contemplada com o ProUCA. Revista Cippus/ UNILASALLE. v. 2 n. 1. p. 82-99, maio/2013.

SEABRA, Carlos. A onda dos microcontos. Revista Língua portuguesa, Brasil, Abril, 2010.

SILVA, Maria N. dos S; CAMPOS, Karla K. de S; SILVA, Abdoral I. da. Uma proposta didática: a inserção do gênero microconto em sala de aula por meio do aparelho celular. Revista de Pesquisa Interdisciplinar, Cajazeiras, n.2, suplementar, p. 606 - 614. set./2017.

TASSINARI, A. O Instante Radiante - Henri Cartier-Bresson. In: MAMMI, L.; Schwarcz, L. M. (Org.). 8x fotografia: ensaios. São Paulo: Companhia das Letras, 2008. 